\title{
Evaluation of the antimicrobial effect of calcium hydroxide combined to different vehicles
}

Tatiana Dantas Piana ${ }^{a}$, Maria de Fátima Malvar Gesteira ${ }^{a}$, Erica dos Santos Carvalho ${ }^{a}$, Josilene Borges Torres Lima Matos ${ }^{b}$, Mônica Francab ${ }^{\mathrm{b}}$, Leandro Miranda de Araújo ${ }^{\mathrm{a}}$, Silvio José Albergaria da Silva ${ }^{\mathrm{a}}$

\section{ABSTRACT}

Objective: To evaluate the potentiating effect of different substances in antimicrobial action of calcium hydroxide.

Methods: The agar diffusion method, was used with well technique, to analyze seven substances associated to calcium hydroxide to make some pastes, they are: chlorexidine, saline, anesthetic, malvatricin, propolis, hypochlorite, paramonochlorophenol.

Results: The pastes with malvatricin and paramonochlorophenol presented greater inhibition zones against Enterococcus faecalis.

Conclusion: There was potentialization in antimicrobial effect of calcium hydroxide when associated to paramonochlorophenol and to malvatricin especially against Enterococcus faecalis. Low increase of the antimicrobial capacity was observed when using chlorexidine as vehicle to calcium hydroxine paste.

Key words: Calcium hydroxide; Propolis; Paramonochlorophenol

\section{Avaliação do efeito antimicrobiano do hidróxido de cálcio associado a diferentes veículos}

\section{RESUMO}

Objetivo: Avaliar o efeito potencializador de diferentes substâncias na ação antimicrobiana do hidróxido de cálcio.

Metodologia: Utilizou-se a técnica de difusão em ágar, pelo método do poço, sendo analisadas sete substâncias associadas ao hidróxido de cálcio para formar pasta, são elas: clorexidina, soro fisiológico, anestésico, malvatricin, própolis, hipoclorito e paramonoclorofenol.

Resultados: As pastas com malvatricin e paramonoclorofenol apresentaram maior halo de inibição frente à Enterococcus faecalis.

Conclusão: Houve potencialização do efeito antimicrobiano do hidróxido de cálcio quando associado ao paramonoclorofenol e ao malvatricin principalmente frente ao Enterococcus faecalis. Pouco aumento da capacidade antimicrobiana foi observado quando a clorexidina foi utilizada como veículo na pasta de hidróxido de cálcio.

Palavras-chave: Hidróxido de cálcio; Própolis; Paramonoclorofenol a Department of Dentistry, Division of Endodontics Federal University of Bahia, Salvador, Bahia, Brazil b Department of Microbiology, Federal University of Bahia, Salvador, Bahia, Brazil 


\section{INTRODUCTION}

Difficulty to eliminate microorganisms, which remain in the root canal system, even after the sanitization procedure, demonstrates the need for the use of an intracanal medication after biomechanical preparation and before the root canal filling $[1,2,3]$.

The intracanal medicament is more likely to reach unaffected areas by the endodontic files and the chemical substance, in view of it stays longer in the root canal than the irrigants. The choice of an intracanal dressing is based on some characteristics presented by the material, and among the desired properties, it is considered of great importance: antimicrobial activity, biocompatibility, broad spectrum of action, prolonged activity, not stain the dental structures, be hypoallergenic and easy to be removed [4]. However, a compound having all of these characteristics has not yet been used in clinical practice.

One of the substances widely used as intracanal medication is calcium hydroxide, singly used or combined with another substance in order to potentiate their effect $[5,6]$. The main benefit of calcium hydroxide as intracanal medication is related to its bactericidal effect given by its high $\mathrm{pH}$, once the microorganisms are not able to survive in a highly alkaline environment [7].

Modern endodontic is looking for biocompatible substances to act in the root canal and periapical region. The use of herbal medicine has been evaluated and encouraged, due to great utility of the therapeutic properties, such as the propolis [8]. It has been noticed that the Propolis is a substance highlighted in reason of its properties such as anti-inflammatory, antimicrobial, anesthetic, antitoxic, antioxidant, immuno-stimulatory, anti-tumor and healing [9]. In addition to these properties propolis is also antifungal, antiprotozoal and antiviral [10].

Another interesting substance is tyrothricin (20 to $25 \%$ gramicidin and tyrocidine about $60 \%$ ), present in the Malvatricin mouthwash, which is derived from Bacillus brevis. Depending on the concentration, it may have bacteriostatic or bactericidal action. It acts on Gram-negative bacteria and has lasting topical action. The mouthwash also features mallow extract and other components in its composition, existing formulations without tyrothricin. Tests conducted with Malvatricin, whose active ingredients are mauve, sodium fluoride and xylitol, demonstrated effectiveness of mouthwash on Enterococcus faecalis and Staphylococcus aureus [11].

Among the intracanal medications, the camphorated paramonochlorophenol (PMCC) is distinguished, face to its effectiveness to combat the microorganisms of the canal. The combination of PMCC with other substances has been proposed aiming to enhance the antimicrobial activity and reduce cytotoxicity of the drug [12]. The association of this substance with calcium hydroxide has been used in order to increase the spectrum of action mainly against facultative and aerobic bacteria. Although knowing the cytotoxic potential of PMCC, the combination of substances is effective in eliminating strict and facultative anaerobic bacteria located in the dentinal tubules [13].

Another interesting substance that can be used in endodontics is the chlorhexidine digluconate, due to the broad spectrum of activity mainly against Enterococcus faecalis and Candida albicans, added to calcium hydroxide pastes [7]. Into the root canal at concentration of $2.0 \%$ the chlorhexidine is able to diffuse across the dentinal tubules and to be effective in the root surface against the microorganisms [14].

Sodium hypochlorite is a substance used to disinfect the root canal and its properties are related to their ability to dissolve organic tissue, to be antimicrobial, have an alkaline $\mathrm{pH}$, to promote cleaning, to be deodorant and have low surface tension $[15,16]$.

Considering the diversity of substances found on the market and searching for more efficient medication in the more resistant microorganisms to combat certain medications, the aim of this study is to evaluate the potential effect of different substances in the antimicrobial action of calcium hydroxide.

\section{METHODS}

\section{Vehicles for calcium hydroxide/strains used}

Four possible solutions were tested in this study as vehicles on the use of intracanal calcium hydroxide: $0.2 \%$ chlorhexidine digluconate, malvatricin, paramonochlorophenol and propolis. These solutions were evaluated in relation to antimicrobial potential and synergistic action with the calcium hydroxide on standard strains of Staphylococcus aureus, Escherichia coli, Pseudomonas aeruginosa, Enterococcus faecalis and Candida albicans kept in the microbiology laboratory of the institute of health sciences (IHS). As positive control was used the 1\% sodium hypochlorite, by its action known disinfectant. And as negative control the saline and anaesthetic, by not having any antimicrobial action.

\section{Activation of the strains and standardization of inoculant}

The inoculant was conducted using the method of direct suspension of colonies, from cultures between 18 and 20 hours of growth. Were used between 8 to 10 colonies of each microorganism, to muddy $5 \mathrm{ml}$ of sterile saline solution, and this suspension of colonies in saline has been compared visually to a 0.5 McFarland, with the aid of black background with white lines. This procedure has the purpose of obtaining standardized inoculants, and may add more colonies or a little more of sterile saline, when necessary. Thus, with the turbidity equivalent to the scale obtained inoculants corresponding to UCF $1 \times 10^{8} / \mathrm{ml}$ of solution.

\section{Evaluation of the antibacterial activity of the solutions vehicles by diffusion in agar through the technique of the well}

In order to evaluate the activity of tested solutions were used Petri plates $(140 \mathrm{~mm} / 15 \mathrm{~mm})$ containing $55 \mathrm{ml}$ of 
Trypticase Soy Agar culture medium (TSA) to the bacterial strains, and Sabouraud Agar, for Candida albicans. The 10 plates were inoculated individually with a sterile swab and saturated with the different microbial suspensions (E. faecalis, C. albicans, S. aureus, E. coli and P. aeruginosa). The swab was compressed to the internal wall of the tube to remove excess inoculum, and seeded on the surface of the agar in three directions uniformly, by the seeding for dissemination technique.

For the preparation of wells where tested solutions were added, metallic molds cylinders (PR) $5 \mathrm{~mm}$ in diameter and $5 \mathrm{~mm}$ thick were constructed, with a welding device (HUMPA) and needle holder. The cylinders were properly sterilized by autoclaving to avoid contamination.

In each plate containing the microorganisms were produced six wells with the support of metalic cylinders and a properly sterilized forceps, being the handler with sterile surgical glove. The wells were completely filled with the vehicle solutions: $0.2 \%$ chlorhexidine, saline (negative control), anesthetic solution (negative control), malvatricin, propolis, and $1 \%$ sodium hypochlorite (positive control); inserted with the support of automatic pipette and sterile tips. Due to the volatility property and possible interference of PMC inhibition zone on the other substances, its antimicrobial activity was tested using eight Petri dishes $(90 \mathrm{~mm} / 15 \mathrm{~mm})$ containing $20 \mathrm{~mL}$ of TSA for bacterial strains; and two plates with Sabouraud Agar for Candida albicans, individually seeded with different standardized microbial suspension, as previously described. In each plate was one well made with $5 \mathrm{~mm}$ diameter and $5 \mathrm{~mm}$ thickness each, where it was deposited paramonochlorophenol. All plates were incubated in a greenhouse at $37^{\circ} \mathrm{C}$ for 24 hours. The experiment was conducted aseptically, near the Bunsen burner, and in duplicate (10 large plates and 10 small plates -8 with the TSA and 2 with the Sabouraud).

\section{Evaluation of the synergistic effect of different substances with calcium hydroxide after manipulation in paste form by diffusion in agar through the technique of the well}

To evaluate the antimicrobial activity of the different pastes were used immediately after manipulation ten Petri dishes $(140 \mathrm{~mm} / 15 \mathrm{~mm})$, seeded individually with different standardized microbial suspension as previously described. In each plate six wells were made with $5 \mathrm{~mm}$ diameter and $5 \mathrm{~mm}$ thick each. The wells of each plate were filled with paste 1 - Calcium hydroxide + chlorhexidine; paste 2 - Calcium hydroxide + malvatricin; paste 3 - Calcium hydroxide + propolis; paste 4 - Calcium hydroxide + anesthetic solution; paste 5 - Calcium hydroxide + saline; paste 6 - Calcium hydroxide + hypochlorite. To evaluate the paste 7 - (calcium hydroxide + paramonochlorophenol) were used separate plates with single wells to avoid possible interference of volatility characteristic thereof. The pastes were obtained by mixing calcium hydroxide pro-analysis at a ratio of $0.08 \mathrm{~g}$ of powder to $80 \mu \mathrm{l}$ saline, chlorhexidine, anesthetic, malvatricin; and $160 \mu \mathrm{l}$ of propolis and paramonochlorophenol to obtain the same consistency of the paste. All of them were handled with trowel No. 24 in properly sterilized glass plate. The plates were incubated in a greenhouse at $37^{\circ} \mathrm{C}$ for 24 hours. This stage of the study was also performed aseptically and in duplicate.

To evaluate the diffusion of the paste was used a plate with the substances, which were tested without inoculation of microorganisms.

\section{Evaluation of inhibition halos}

After 24 hours of incubation an inspection was carried out with "unaided eye" of the presence or absence of inhibition halos of microbial growth, as well as measurement of the diameters of halos with a millimeter ruler. The results were then grouped in a table of measurements in millimeters and the largest inhibition halos were characterized as having better result.

\section{RESULTS}

Table 1 shows in vitro results of the difference between the vehicles evaluated in relation to the antimicrobial activity to micro-organisms, without the use of calcium hydroxide. Among the seven substances only saline and anesthetic showed no antimicrobial activity against any of the five micro-organisms, as expected.

Table 1. Smaller halo $(\mathrm{mm})$ microbial growth inhibition produced by fluids tested front the 5 species of microorganisms.

\begin{tabular}{lccccccc}
\hline \multicolumn{1}{c}{ Sample } & \multicolumn{7}{c}{ Petri dishes with liquid } \\
& A & B & C & D & E & F & G \\
S. aureus & 17 & - & - & 25 & 14 & 15 & 21 \\
C. albicans & 10 & - & - & - & 7 & 57 & 27 \\
E. faecalis & 14 & - & - & 11 & 8 & 7 & 12 \\
E. coli & 15 & - & - & - & - & 12 & 18 \\
P. aeruginosa & 14 & - & - & - & 16 & 12 & \\
\hline
\end{tabular}

A - Chlorhexidine 0,2\%; B - Saline; C - Anesthetic; D - Malvatricin; E - Propolis; F - Hypochlorite; G - Paramonoclorofenol.

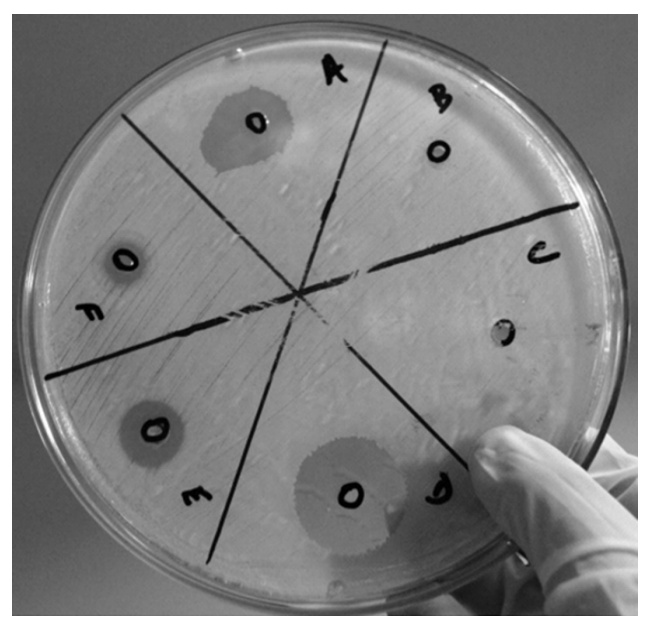

Figure 1. Presence of inhibition halos chlorhexidine, malvatricin, própolis and hypochlorite amid TSA with $E$. faecalis. 
On the other hand, chlorhexidine, hypochlorite and paramonochlorophenol have antimicrobial action against all tested microorganisms, which confirms the antimicrobial action of these substances. The other two tested vehicles, malvatricin and propolis were effective against only specific micro-organisms; the malvatricin acted against $S$. aureus and E. faecalis and propolis that got better result than the malvatricin, acted against everyone, except against $E$. coli.

Furthermore, the substance that showed greater inhibition halo was hypochlorite to C. albicans, followed by paramonochlorophenol.

Table 2 shows the vehicles associated with the paste, to evaluate which vehicle enhances the antimicrobial action of calcium hydroxide.

The inhibition halos with the five microorganisms were similar when compared between saline and anesthetics. These halos were lower in comparison with other substances, showing that all four tested substances (chlorhexidine, propolis, hypochlorite and paramonochlorophenol) potentiated the antimicrobial action of calcium hydroxide.

The lower inhibition halo was the paste with saline and anesthetic against E. faecalis and saline against $E$. coli. The largest inhibition halo was the paste with paramonochlorophenol against $P$. aeruginosa.

Table 2. Average in $\mathrm{mm}$ of the microbial growth inhibition halos produced by calcium hydroxide pastes with different vehicles, tested the 5 species of microorganisms.

\begin{tabular}{lccccccc}
\hline \multicolumn{1}{c}{ Sample } & \multicolumn{7}{c}{ Petri dishes with paste } \\
& A & B & C & D & E & F & G \\
S. Aureus & 15 & 14 & 14 & 22 & 14 & 14 & 24 \\
C. Albicans & 12 & 10 & 12 & 15 & 11 & 13 & 20 \\
E. Faecalis & 11 & 8 & 8 & 17 & 12 & 11 & 17 \\
E. Coli & 12 & 8 & 10 & 11 & 9 & 11 & 20 \\
P. Aeruginosa & 18 & 18 & 18 & 17 & 24 & 18 & 25 \\
White & 17,0 & & 19,0 & 19,0 & 19,0 & 18,0 & 20,0 \\
\hline
\end{tabular}

A - Chlorhexidine 0,2\%; B - Saline; C - Anesthetic; D - Malvatricin; E - Propolis; F- Hypochlorite; G - Paramonoclorofenol.
The pastes that were more effective against $E$. faecalis were pastes with malvatricin and paramonochlorophenol. It is also noticed more effective pastes with malvatricin and paramonochlorophenol against $S$. aureus, C. albicans and $E$. faecalis. For E. coli, largest inhibition halos were found in the paste and paramonochlorophenol chlorhexidine.

\section{DISCUSSION}

Since 1920, when calcium hydroxide was introduced in dentistry by Herman, this drug has been used in numerous situations in clinical practice. The properties of the calcium hydroxide has been studied by several authors. The alkaline $\mathrm{pH}$ and calcium release is extremely important to the efficiency of the material. The action of calcium hydroxide against E. faecalis and other microorganisms has been discussed in the literature, because it is frequent in recurrent injuries and is resistant to several antibiotics [5].

In the present study, we used standard strains of Staphylococcus aureus, Escherichia coli, Pseudomonas aeruginosa, Enterococcus faecalis and Candida albicans, since E. faecalis and C. albicans are associated with secondary infections, and consequently to the failure of the endodontic treatment, while S. aureus, E. coli and $P$. aeruginosa are microorganisms described in the literature as reference for evaluating antimicrobial susceptibility. The experiment was performed in duplicate, because these are standard strains that provide reliable results in just two replicates of each material, thus sufficient to analyze the results.

The results obtained from this study showed that the saline and the anaesthetic had antimicrobial effect, which is in agreement with the research of Dotto et al. [17] (2006) found that lower efficiency of calcium hydroxide with anesthetic against $E$. faecalis. This fact was evident due to the smaller inhibition halo to the pastes that used the combination of anaesthetic and calcium hydroxide with saline.

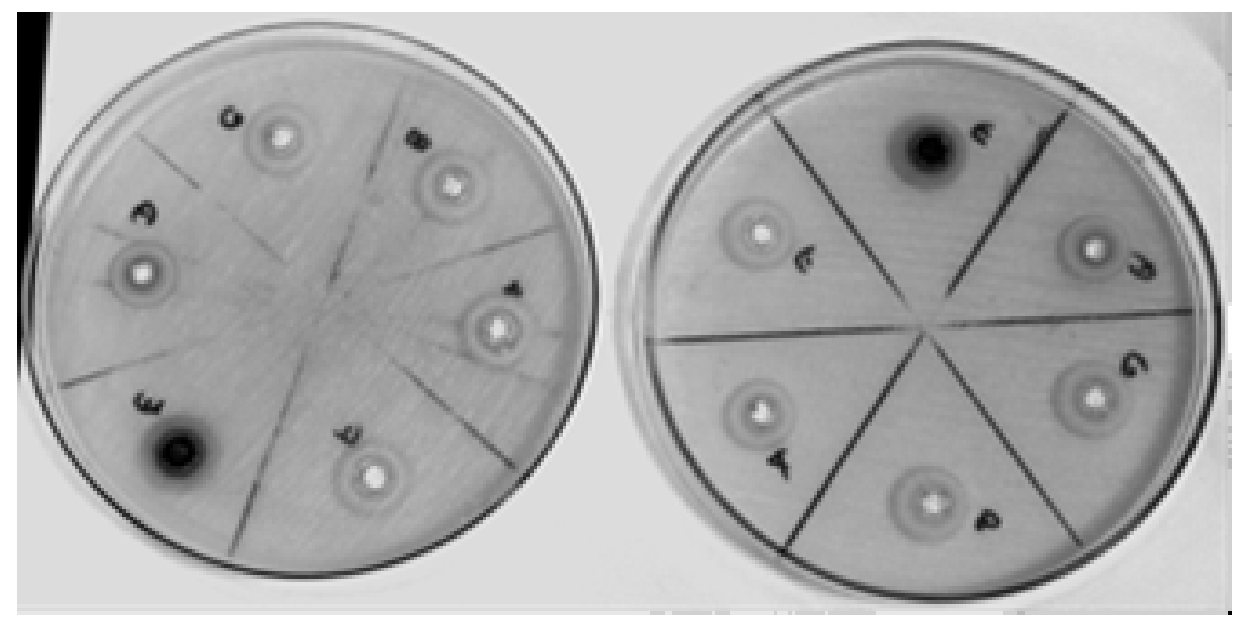

Figure 2. Shows the halos of inhibition of pastes amid TSA in the presence of $E$. faecalis. 
In this study, the paste containing chlorhexidine had a better result compared to saline and anesthetic face to all five microorganisms. Evans et al. [18] (2003) observed an additive or synergistic effect on the antimicrobial action of the mixture of calcium hydroxide with chlorhexidine as well. Ercan et al. [19] (2007) state that the combination of calcium hydroxide with chlorhexidine in the manipulation of intracanal medication has been widely analyzed and defended, especially in cases of persistent apical periodontitis associated with pulp necrosis or failed endodontic treatment, even with the limited availability of information about this association. In contrast, others studies demonstrate no improvement on antimicrobial effect in the association of calcium hydroxide with the chlorhexidine, but showed that calcium hydroxide does not lose its antimicrobial properties with the mixture $[20,21]$.

Comparing the propolis paste with the saline and anesthetic pastes, it showed greater inhibition halo. This result agrees with the result presented by Ehsani et al. [22] (2013), who observed effectiveness of propolis paste in the control of dental infection in vitro against $E$. faecalis. However, these studies contradict the study of Só et al. [23] (2011) who found no inhibition halos against $E$. faecalis but does not tested propolis paste with calcium hydroxide, but only propolis and concluded that this is not effective.

In this study it was also observed that the substance associated with the calcium hydroxide in which presented the highest inhibition halo against $E$. faecalis and $C$. albicans was the paramonochlorophenol, being larger halos in association in comparison to the isolated vehicles, what is in accordance with other studies $[13,21]$.These results are not in agreement with the findings of Nagem Filho et al. [4] (2007), which observed larger inhibition halos for pure paramonochlorophenol and smaller halos when the paramonochlorophenol was associated with calcium hydroxide. Also disagrees with the study presented by Dotto et al. [17] (2006), where was not observed inhibition halo of association of paramonochlorophenol with calcium hydroxide, however they found antimicrobial activity of this association.

The malvatricin, in this study, had better result against $E$. faecalis, C. albicans and $S$. aureus compared to chlorhexidine, saline, anesthesic and propolis. Others researches have demonstrated effectiveness of the mouthwash against S.mutans, S. salivarius, S.oralis and L. casei $[11,25]$. The malvatricin is presented as promising substance to be evaluated as a vehicle in association with calcium hydroxide in the endodontic treatment, however there are no studies about the use of malvatricin in endodontics. Thus, it is therefore essential to be realized further studies in vitro and in vivo about such medication to comprove its efficacy in clinical practice.

\section{CONCLUSION}

The results of this study demonstrate that there was antimicrobial effect enhancement of calcium hydroxide when associated with the camphorated paramonoclorofenol and the malvatricin primarily against E. faecalis and It was observed little increase in the antimicrobial capacity when the chlorhexidine was used as a vehicle of calcium hydroxide paste.

\section{REFERENCES}

1. Maia Filho EM, Maia CCR, Bastos ACSC, Novais TMG. In vitro antimicrobia effect of different endodontic medications and própolis on Enterococcus faecalis. RGO Porto Alegre 2008;56(1):21-5

2. Carvalho ES, Malvar MFG, Albergaria SJ. Evaluation of marginal infiltration of four provisional sealers after the use of auxiliary chemicals in endodontic instrumentation. Rev. Fac. Odontol. Porto Alegre 2008;49(3):20-3.

3. Pereira L, Nabeshima CK, Britto MLB, Pallotta RC. Evaluation of $\mathrm{pH}$ of substances used as intracanal medication in different vehicles. RSBO 2009;6(3):245

4. Nagem Filho $H$, Nagem $H D$, Coutinho $K Q$, Carvalho PRMA, Fiuza CT Properties of paramonoclorofenol camphor and paramonoclorofeno camphor associated with the calcium hydroxide. Pesq. Bras. Odontoped. Clin. Integr., João Pessoa 2007;7(3):235-9.

5. Camargo CHR, Afonso SE, Valera MC, Mancini MNG, Bernardineli N Oliveira LD. Evaluation of $\mathrm{pH}$ and release of calcium ions, in the use of calcium hydroxide pastes. Cienc Odontol Bras 2003 jan.-mar.;6(1):51-9.

6. Oliveira EPM, Irala LED, Santos AR, Melo TAF. Evaluation of the antimicrobial action of four calcium hidroxide-based formulation as intracanal medication used. RFO 2010; 15(1): 35-9.

7. Barbin EL. Chemical analysis of chlorhexidine mixe dor not with calcium hydroxide. Thesis (PhD) - Dentristry college of Ribeirão Preto, São Paulo 2008. 148p

8. Costa EMMB, Esmeraldo MRA, Carvalho MGF, Daniel RLDP, Pastro MF Silva Júnior FL. Evaluation of the antimicrobial action of propolis and substances used in Endodontics on Enterococcus faecalis. Pesq Bras Odontoped Clin Integr 2008;8(1):21-5. https://doi.org/10.4034/1519.05 01.2008.0081.0005

9. Santos FA, Bastos EMA, Uzeda M, Carvalho LM, Farias LM, Moreira ESA Braga FC. Antibacterial activity of Brazilian própolis and fractions against oral anaerobic bacteria. J Ethnopharmacol 2002;80(1):1-7. https://doi org/10.1016/S0378-8741(02)00003-X

10. Pereira AS, Seixas FRMS, Aquino Neto FR. Propolis: 100 years of research and its future prospects. Química Nova 2002;25(2):321-6. https://doi. org/10.1590/S0100-40422002000200021

11. Monfrim R, Ribeiro MC. In vitro evaluation of mouthwashes on the microbiota of saliva. Assoc. Paul. Cir. Dent 2000;54(5):400-7. https://doi. org/ 10.1111/j.1601-5037.2007.00230.x

12. Mello-Moura AC, Fanaro J, Nicoletti MA, Mendes FM, Wanderley MT, Guedes-Pinto AC. Variability in the proportion of components of iodoformbased Guedes-Pinto paste mixed by dental students and pediatric dentists. Indian J Dent Res. 2011 Nov-Dec;22(6):781-5. https://doi org/10.4103/0970-9290.94668

13. Lima RA, Carvalho CB, Ribeiro TR, Fonteles CS. Antimicrobial efficacy of chlorhexidine and calcium hydroxide/camphorated paramonochlorophenol on infected primary molars: a split-mouth randomized clinical trial. Quintessence Int. 2013 Feb;44(2):113-22. https://doi.org/10.3290/j. qi.a28932

14. Nair, PNR. On the causes of persistent apical periodontitis: a review. Int Endod J. 2006;39:249-81. https://doi.org/10.1111/j.13652591.2006.01099.x

15. Estrela C, Estrela CRA, Barbin EL, Spanó JCE, Marchesan MA, Pecora JD. Mechanism of action of sodium hypochlorite. Brazilian Dental Journa 2002;13(2):113-7. https://doi.org/10.1590/S0103-64402002000200007

16. Guida A. Mechanism of action of sodium hypochlorite and its effects on dentin.Minerva Stomatol. 2006 Sept;55(9):471-82

17. Dotto SR, Travasos RMC, Ferreira R, Santos R, Wagner M. Evaluation of the antimicrobial action of different medications used in endodontics. Rev. Odonto Ciência 2006;21(53):266-9.

18. Evans MD, Baumgartner C, Khemaleelakul S, Xia T. Efficacy of calcium hydroxide: chlorhexidine paste as an intracanal medication in bovine dentin J. Endodontics 2003;29(5):338-9. https://doi.org/10.1097/00004770$200305000-00005$

19. Ercan E, Dalli M, Duülgergil CT, Yaman F. Effect of intracanal medication with calcium hydroxide and $1 \%$ chlorhexidine in endodontic retreatment cases with periapical lesions: an in vivo study. J Formos Med Assoc. 2007 Mar;106(3):217-24. https://doi.org/10.1016/S0929-6646(09)60243-6 
20. Jhamb S, Nikhil V, Singh V. An in vitro study of antibacterial effect of calcium hydroxide and chlorhexidine on Enterococcus faecalis. Indian J Dent Res 2010;21:512-4. https://doi.org/10.4103/0970-9290.74222

21. Silveira CF, Cunha RS, Fontana CE, de Martin AS, Gomes BP, Motta $\mathrm{RH}$, et al. Assessment of the Antibacterial Activity of Calcium Hydroxide Combined with Chlorhexidine Paste and Other Intracanal Medications against Bacterial Pathogens. Eur J Dent. 2011;5:1-7.

22. Ehsani M, Marashi MA, Zabihi E, Issazadeh M, Khafri S. A Comparison between Antibacterial Activity of Propolis and Aloe vera on Enterococcus faecalis (an In Vitro Study). Int J Mol Med celular 2013;2:110-6.

23. Só MVR, Wagner MH, Rosa RA, Telles L, Colpani F, Henz S, Magro $\mathrm{ML}$. Antimicrobial activity in vitro of a suspension of proposis against Enterococcus faecalis. RFO 2011;16(3):277-81.
24. Cavalcanti YW; Almeida LFD; Costa MMTM; Padilha WWN. Antimicrobial activity and $\mathrm{pH}$ evaluation of Calcium Hydroxide associated with natural products. Braz Dent Sci 2010 July-Dec;13(8):49-54

25. Da Silva NB, Alexandria AK, De Lima AL, Claudino LV, De Oliveira Carneiro TF, Da Costa AC, Valença AM, Cavalcanti AL. In vitro antimicrobial activity of mouth washes and herbal products against dental biofilm-forming bacteria. See comment in PubMed Commons belowContemp Clin Dent. 2012 July;3(3):302-5. https://doi.org/10.4103/0976-237X.103623 